\title{
Chalcogen Bonds in Small-Organic Molecule Compounds Derived from the Cambridge Structural Database (CSD)
}

\author{
Albert S. Lundemba1, Dikima D. Bibelayi', Philippe V. Tsalu², Peter A. Wood ${ }^{3}$, Jason Cole², \\ Jean S. Kayembe' ${ }^{1}$ Zephirin G. Yav ${ }^{*}$
}

${ }^{1}$ Department of Chemistry, University of Kinshasa, Kinshasa XI, The Democratic Republic of Congo

${ }^{2}$ AIT-Austrian Institute of Technology, Vienna, Austria

${ }^{3}$ The Cambridge Crystallographic Data Centre, Cambridge, UK

Email: *zgyav@yahoo.fr

How to cite this paper: Lundemba, A.S., Bibelayi, D.D., Tsalu, P.V., Wood, P.A., Cole, J., Kayembe, J.S. and Yav, Z.G. (2021) Chalcogen Bonds in Small-Organic Molecule Compounds Derived from the Cambridge Structural Database (CSD). Crystal Structure Theory and Applications, 10, 57-69. https://doi.org/10.4236/csta.2021.104005

Received: September 82021

Accepted: November 8, 2021

Published: November 11, 2021

Copyright $\odot 2021$ by author(s) and Scientific Research Publishing Inc. This work is licensed under the Creative Commons Attribution International License (CC BY 4.0).

http://creativecommons.org/licenses/by/4.0/

\begin{abstract}
Growing interest in non-covalent interactions involving chalcogen atoms has been ascribed to their importance in crystal engineering, molecular recognition and macromolecular edifices. The present study is dealing with chalcogen bonds involving divalent Sulphur, Selenium and Tellurium atoms, acting as sigma-hole donors, in small-molecule compounds using the Cambridge Structural Database (CSD) in conjunction with $a b$ initio calculations. Results derived from CSD surveys and computational study revealed that nucleophiles formed complexes with the chalcogen-bond donors $R_{1}-X-R_{2}(X=S$, Se or $\mathrm{Te}$ ). The main forces stabilizing the complexes were chalcogen bonds, enhanced by dispersion interactions. Complexation pattern and energetics show that nucleophile bonding at divalent $\mathrm{S}$, Se and Te atoms is a relatively strong and directed interaction. The bond consists of a charge transfer from a nucleophile atom lone pair to an $\mathrm{X}-\mathrm{R}_{1}$ or $\mathrm{X}-\mathrm{R}_{2}$ antibonding orbital.
\end{abstract}

\section{Keywords}

Chalcogen Bond, CSD, $A b$ Initio Calculation, Interaction Geometry, Interaction Energy

\section{Introduction}

There are numerous computational studies reporting on interactions of divalent chalcogen atoms (acting as $\sigma$-hole bond donors), mostly in small-inorganic molecule compounds (Pal, D. \& Chakrabarti, P., 2001 [1]; Politzer, P. et al., 2007 
[2]; Bleiholder, C. et al., 2006 [3]; Clark, T. et al., 2007 [4]; Ramos, L. A. et al., 2010 [5]; Politzer, P. et al., 2010 [6]; Politzer, P. et al., 2013 [7]; Politzer, P. \& Murray, J. S., 2013 [8]; Politzer, P. et al., 2014 [9]; Pandiyan, B. V. et al., 2016 [10]; Zabardasti, A. et al., 2017 [11]; Bauza, A. \& Frontera A., 2018 [12]; 2019 [13]; 2020 [14]). Computational studies also showed that positive electrostatic potentials as well as $\sigma$-hole interactions are strongly affected by the environment of the covalently bonded chalcogen atom (Murray et al., 2007 [15]; Murray \& Politzer, 2011 [16]; Politzer \& Murray, 2017 [17]).

To understand the intermolecular interaction between chalcogen atoms $(\mathrm{O}, \mathrm{S}$, $\mathrm{Se}, \mathrm{Te}$ ) quantum chemistry calculations using some model systems have been performed. Previous investigation on the intermolecular interactions between two molecules containing elements of group VI showed that the chalcogen-chalcogen interaction dominates and hydrogen bonding plays only a minor role in aggregates with heavier atoms (Bleiholder, C. et al., 2006 [3]). The strength of the chalcogen interaction increased steadily from oxygen via sulphur to selenium and peaked around $6 \mathrm{kcal} / \mathrm{mol}$ for tellurium. The bond strength also increased when adding an electron withdrawing substituent such as the cyanide group CN.

However, experimental data supporting chalcogen-bonded complexes are rare and scarce (Goettel, J. T. \& Gerken, M., 2016 [18]; Karjalainen, M. M. et al., 2016 [19]). Analysis of consistent experimental data dealing with chalcogen interactions in organic molecules may be crucial due to their nature, importance and implications in the chemical, biological and medicinal areas. Theoretical study in addition to the data analysis is useful to provide a better understanding of the interaction and to guide its application in a wide variety of fields, like crystal engineering and drug design. The present study aims at using crystallographic data derived from the Cambridge Structural Database (CSD) to investigate on $\sigma$-hole interactions in small-organic molecule compounds containing divalent chalcogen atoms in conjunction with ab initio calculations in order to provide consistent insights into the nature of chalcogen bonding at divalent $S$, Se and Te atoms acting as $\sigma$-hole bond donors. This is of some interest as previous studies of inorganic chalcogen-bonded complexes reported that the chalcogen bond was a relatively strong and nearly linear interaction. They also showed the dependence of the interaction strength on the environment of chalcogen atoms [15] [16] [17].

\section{Materials and Methods}

\subsection{CSD Analysis}

Work CSD version 5.41 plus November 2019 update was used to perform the analysis of sulfur, selenium and tellurium compounds, this version contains a total of 1,034,174 structural entries. The CSD-System program ConQuest (Bruno et al., 2002 [20]) was used to question the database substructure searches to match selenium containing systems, as well as relevant non-bonded 
interactions. The following secondary search criteria were employed: 1) atomic coordinates present in the entry; 2) error-free after CSD evaluation; 3) no disorder in the crystal structure; 4) no polymeric (catena) bonding; 5) no powder studies; 6) crystallographic R-factor $<0.10 ; 7$ ) only organic structures (according to standard CSD definitions). Any specific variations of these criteria are noted in the text. In the results and discussion section, atoms and groups will be referred to by their coordination number as a superscript, with $\mathrm{N}^{3}$, for example, denoting a three-coordinate nitrogen atom. The CSD-System program Mercury (Macrae et al., 2006 [21], 2008 [22]) was used for structure visualization, while numerical analysis of geometrical data retrieved by ConQuest was carried out using the Data Analysis Module implemented within Mercury (Sykes et al., $2011[23])$.

The geometrical parameters $\delta$ (intermolecular distance) and $\theta$ (angle) of the chalcogen interaction are defined according to Scheme 1 . The differences between sums of van der Waals radii of interacting atoms $\left(\mathrm{r}_{\mathrm{Ch}}+\mathrm{r}_{\mathrm{QA}}\right)$ and distances $\delta$ represent the "normalized" distances $\Delta$ (Wood et al., 2008 [24]). The values of van der Waals radii reported by Bondi et al. (1964) [25] were used for calculations.
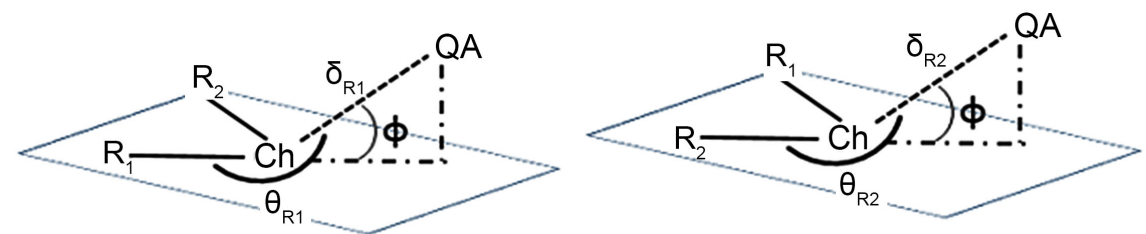

Scheme 1. Ch = chalcogen atom S, Se or Te; $\mathrm{R}_{1}, \mathrm{R}_{2}=$ substituents as illustrated in Table $1 ; \mathrm{QA}=$ nucleophile; $\theta=$ interaction angle; $\delta=$ interaction distance.

\subsection{Computational Study}

The second-order Moller-Plesset perturbation theory MP2 and the density functional theories B3LYP and B3PW91 at basis set 6-311G (3df,2p) were used for calculations, when investigating on S- and Se-containing chalcogen bond donors. Only HF/ chemical model was used for Te chalcogen donors containing $\mathrm{Te}$ atoms.

We use Equations (1) and (2) (Murray et al., 2011 [26]; Lundemba S. et al., 2020 [27]) to perform electrostatic potential $(V)$ in the space around a chalcogen-bond donor, written in atomic units $(\mathrm{au})$, and interaction energy $\left(E_{\text {int }}\right)$ between a chalcogen donor and an acceptor, respectively. Energies $E_{\text {int }}$ are energy minima at $0 \mathrm{~K}$. Large basis sets are used to minimize the problem of correction for the basis set superposition error (Grimme S., 2006 [28]; Politzer P. et al., 2013 [7]).

$$
\begin{aligned}
& V(r)=\sum_{A} \frac{Z_{A}}{\left|R_{A}-r\right|}-\int \frac{\rho\left(r^{\prime}\right) \mathrm{d} r^{\prime}}{\left|r^{\prime}-r\right|} \\
& E_{\text {int }}=E_{\text {complex }}-\left(E_{\text {donor }}+E_{\text {acceptor }}\right)
\end{aligned}
$$


Figure 1 reports examples of molecular models of chalcogen bond used for $a b$ initio calculations.
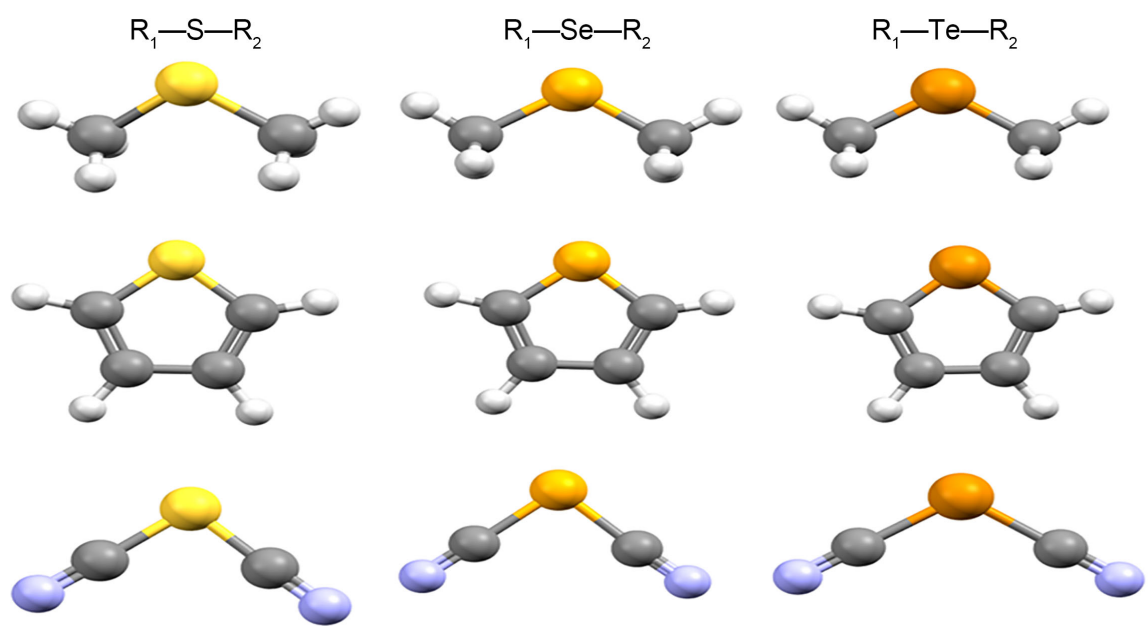

Figure 1. Molecular models of chalcogen-bond donors derived from CSD used for ab initio calculation.

\section{Results and Discussion}

\subsection{CSD Surveys}

\subsubsection{Frequency of Occurrence (FoO)}

CSD analysis reveals that many organic compounds containing divalent chalcogen atoms $R_{1}-X-R_{2}(X=S$, Se or $T e)$ interact with various nucleophile atoms (QA) like N, O, F, P, S, Cl, As, Se, Br, Sb, Te or I. Occurrence frequencies of molecular fragments containing divalent chalcogens $R_{1}-X-R_{2}(X=S$, Se or $T e)$ involved in interactions with $\sigma$-hole acceptors are listed in Table 1(a)-(c).

Table 1. Number $\left(N_{f}\right)$ and occurrence frequency (FoO in \%) of fragments forming intermolecular chalcogen-bonds.

(a) $\mathrm{R}_{1}-\mathrm{S}-\mathrm{R}_{2}$

\begin{tabular}{|c|c|c|c|}
\hline $\mathbf{R}_{1}$ & $\mathbf{R}_{2}$ & $N_{f}$ & FoO \\
\hline C & $\mathrm{C}$ & 13,943 & 70.77 \\
\hline $\mathrm{N}$ & $S$ & 1801 & 9.14 \\
\hline C & $S$ & 1550 & 7.86 \\
\hline C & $\mathrm{N}$ & 624 & 3.17 \\
\hline $\mathrm{N}$ & $\mathrm{N}$ & 623 & 3.16 \\
\hline$S$ & S & 440 & 2.23 \\
\hline C & $\mathrm{P}$ & 81 & 0.41 \\
\hline \multicolumn{2}{|c|}{ Other } & 638 & 3.24 \\
\hline \multicolumn{2}{|c|}{ Total } & 19,700 & \\
\hline
\end{tabular}


(b) $\mathrm{R}_{1}-\mathrm{Se}-\mathrm{R}_{2}$

\begin{tabular}{|c|c|c|c|}
\hline $\mathrm{R}_{1}$ & $\mathbf{R}_{2}$ & $N_{f}$ & FoO \\
\hline C & $\mathrm{C}$ & 1318 & 49.49 \\
\hline $\mathrm{C}$ & $\mathrm{Se}$ & 436 & 16.37 \\
\hline $\mathbf{N}$ & $\mathrm{N}$ & 252 & 9.46 \\
\hline $\mathbf{N}$ & $\mathrm{Se}$ & 192 & 7.21 \\
\hline C & $\mathrm{N}$ & 142 & 5.33 \\
\hline $\mathbf{N}$ & $S$ & 111 & 4.16 \\
\hline $\mathrm{Se}$ & $\mathrm{Se}$ & 80 & 3.00 \\
\hline \multicolumn{2}{|c|}{ Other } & 132 & 4.96 \\
\hline \multicolumn{2}{|c|}{ Total } & 2663 & \\
\hline
\end{tabular}

(c) $\mathrm{R}_{1}-\mathrm{Te}-\mathrm{R}_{2}$

\begin{tabular}{|c|c|c|c|}
\hline $\mathrm{R}_{1}$ & $\mathbf{R}_{2}$ & $N_{f}$ & FoO \\
\hline $\mathrm{C}$ & $\mathrm{C}$ & 379 & 42.78 \\
\hline $\mathrm{C}$ & $\mathrm{Te}$ & 203 & 22.91 \\
\hline $\mathbf{N}$ & $\mathrm{N}$ & 108 & 12.19 \\
\hline $\mathrm{Te}$ & $\mathrm{Te}$ & 59 & 6.66 \\
\hline$S$ & $S$ & 27 & 3.05 \\
\hline $\mathrm{C}$ & $\mathrm{N}$ & 27 & 3.05 \\
\hline $\mathrm{C}$ & $S$ & 21 & 2.37 \\
\hline \multicolumn{2}{|c|}{ Other } & 62 & 6.99 \\
\hline \multicolumn{2}{|c|}{ Total } & 886 & \\
\hline
\end{tabular}

According to those results shows, $\mathrm{C}, \mathrm{C}-\mathrm{X}$ compounds represent the most important group forming intermolecular interactions. It is noteworthy that the hybridization of carbon atoms affects the frequency of occurrence. Analysis of the carbon atom hybridization reveals that the occurrence frequency increases in the sequence $\mathrm{X}-\mathrm{C}_{\mathrm{sp}}<\mathrm{X}-\mathrm{C}_{\mathrm{sp} 3}<\mathrm{X}-\mathrm{C}_{\text {sp2 }}$.

\subsubsection{Interaction Geometry}

Figure 2 shows the propancy of the nucleophile bonding at chalcogen atoms, mainly along the extensions of the covalent bonds X-R.

Donor
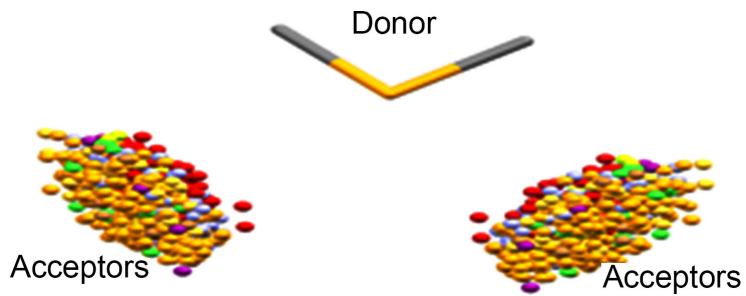

Figure 2. Intermolecular interactions of the C, C-S chalcogen bond donor with nucleophiles. 
It can be seen that nucleophiles mostly interact with chalcogen atoms of the $\sigma$-hole donors $\mathrm{R}_{1}-\mathrm{X}-\mathrm{R}_{2}$ along the extension of the X-R covalent bond.

The geometrical parameters $\theta$ and $\delta$ as described in scheme 1 as well as the length of the chalcogen interaction $\Delta$ are summarized in Table 2.

Table 2. Values of the geometrical parameters $\theta, \delta$ and $\Delta$ of the chalcogen interaction.

\begin{tabular}{cccc}
\hline Geometry & S complexes & Se complexes & Te complexes \\
\hline $\boldsymbol{\theta}\left(^{\circ}\right)$ & {$[162-175]$} & {$[162-178]$} & {$[165-174]$} \\
$\delta(\AA)$ & {$[2.900-3.541]$} & {$[2.701-3.652]$} & {$[2.659-3.960]$} \\
$\Delta(\AA)$ & {$[0.052-0.512]$} & {$[0.090-1.017]$} & {$[0.160-0.951]$} \\
\hline
\end{tabular}

The results in Table 2 report mean bond angles $\theta>160^{\circ}$, which support nearly linear interactions (Politzer et al. 2013 [7]) as illustrated by the pattern of $\mathrm{O}$ bonding at $\mathrm{S}$ atom in Figure 3.

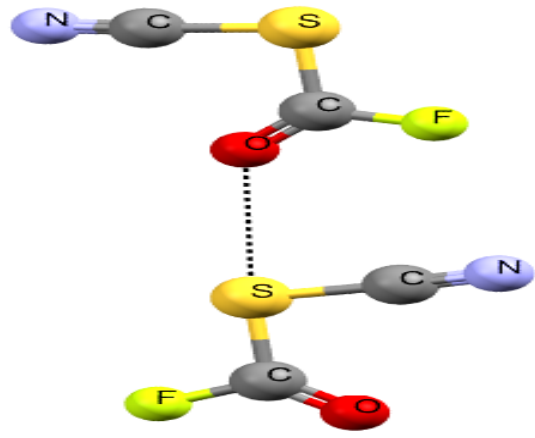

Figure 3. Bond pattern of S-bonded complex.

Nucleophile atom bonding at chalcogen atom with such $\theta$ values is one of main $\sigma$-hole bond characteristics (Politzer et al. 2009 [29], 2013 [7]).

Geometric data also show that mean interaction distances $\delta$ and lengths $\Delta$ have values less than the sums of van der Waals radii of the interacting atoms, demonstrating that the chalcogen interactions are relatively strong. Comparison of bond $\Delta$ values reveals that the ability of chalcogen atoms to interact with nucleophiles increases in the sequence $\mathrm{S}<\mathrm{Se}<\mathrm{Te}$ for a similar environment.

\subsection{Ab Initio Calculations}

\subsubsection{Molecular Electrostatic Potential (MEP) and Lowest Molecular Orbital (LUMO) of Chalcogen Bond Donor}

The lowest molecular orbital (LUMO) of chalcogen bond donors shows a typical pattern depicted in Figure 5 for $\mathrm{NC}-\mathrm{X}-\mathrm{CN}(\mathrm{X}=\mathrm{S}$, Se and Te), while Figure 4 illustrates calculated molecular electrostatic potential surfaces.

As it can be seen, the patterns of MEP and LUMO predict a directional bonding of nucleophiles at divalent chalcogen atoms. Indeed, MEP in Figure 4 features two positive regions, which are located on the chalcogen atoms, and consequently, allow electrostatic interactions with nucleophiles. 


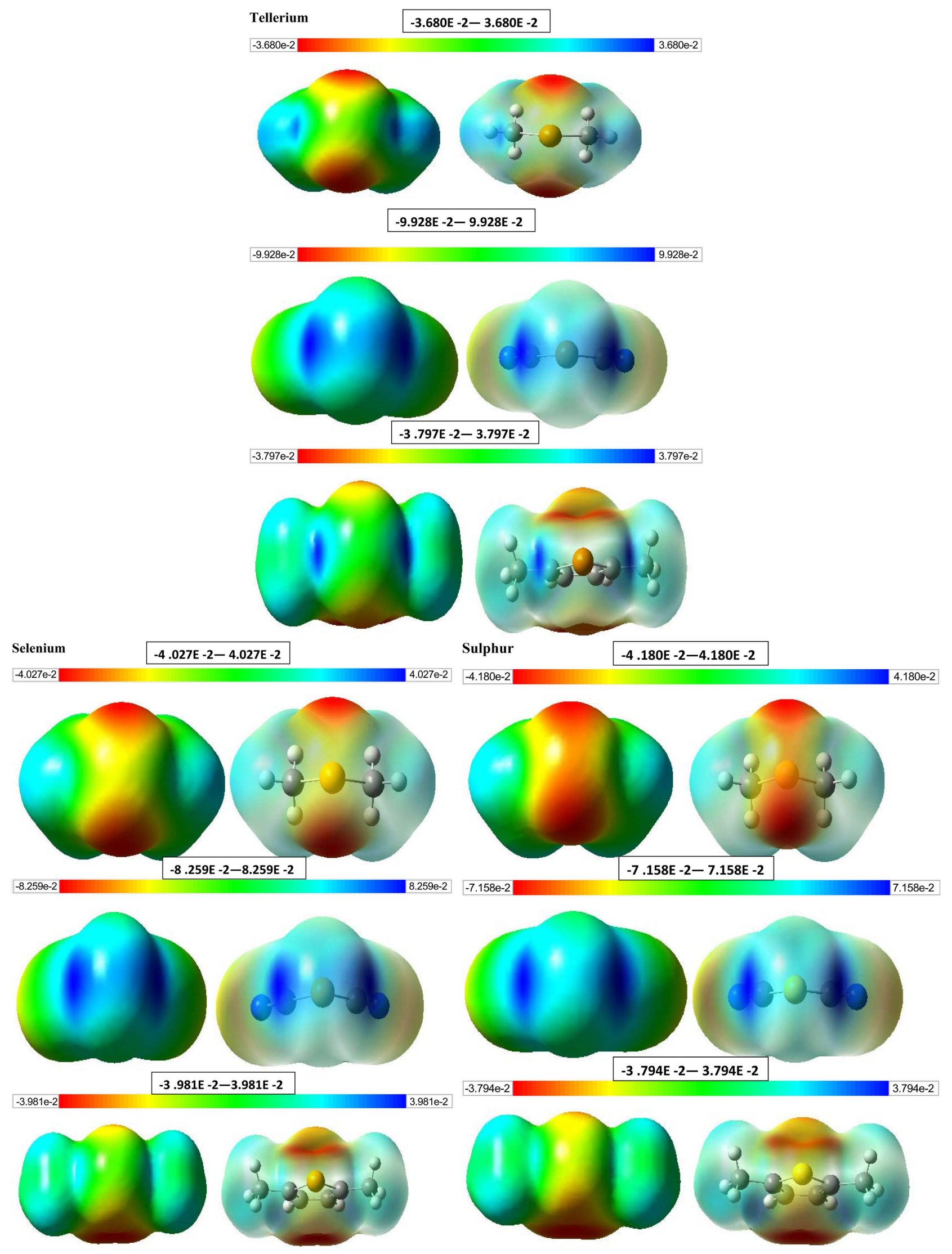

Figure 4. Molecular electrostatic potential surfaces calculated for typical chalcogen S, Se and Te bond donor. 
It is noteworthy that positive region are more or less broad depending on the environment of the chalcogen atom. Values of the most positive electrostatic potential $\left(V_{\mathrm{S}, \max }\right)$ calculated for some examples of chalcogen bond donors are listed in Table 3.

Table 3. Values of $V_{\text {s,max }}$.

\begin{tabular}{cccc}
\hline \multirow{2}{*}{$\mathrm{R}_{1}-\mathrm{X}-\mathrm{R}_{2} \sigma$-hole Donor } & $\mathrm{X}=\mathrm{S}$ & $\mathrm{X}=\mathrm{Se}$ & $\mathrm{X}=\mathrm{Te}$ \\
\cline { 2 - 4 } & 3.92 & 5.99 & 17.77 \\
$\mathrm{H}_{3} \mathrm{C}-\mathrm{X}-\mathrm{CH}_{3}$ & 8.30 & 12.81 & 22.19 \\
$\mathrm{C}_{6} \mathrm{H}_{8} \mathrm{X}$ & 44.48 & 51.13 & 61.66 \\
$\mathrm{NC}-\mathrm{X}-\mathrm{CN}$ & &
\end{tabular}

$\mathrm{V}_{\mathrm{S} \text {, max }}$ values show that the magnitude of the most positive electrostatic potential depends on chalcogen bond donor and substituents $R_{1}$ and $R_{2}$, enhanced by electron withdrawing substituents as previously reported by Murray et al. (2009 [30], 2014 [31]) and Politzer et al. (2007 [2], 2013 [7], 2017 [17]). It increases in the sequence $\mathrm{S}<\mathrm{Se}<\mathrm{Te}$ for similar chalcogen environments. One may then expect an electrostatic interaction between chalcogen-bond donors and nucleophiles (Politzer et al. 2017 [17]).

The lowest molecular orbital (LUMO) of chalcogen bond donors shows a typical pattern depicted in Figure 5 for NC-X-CN $(X=S$, Se and Te).
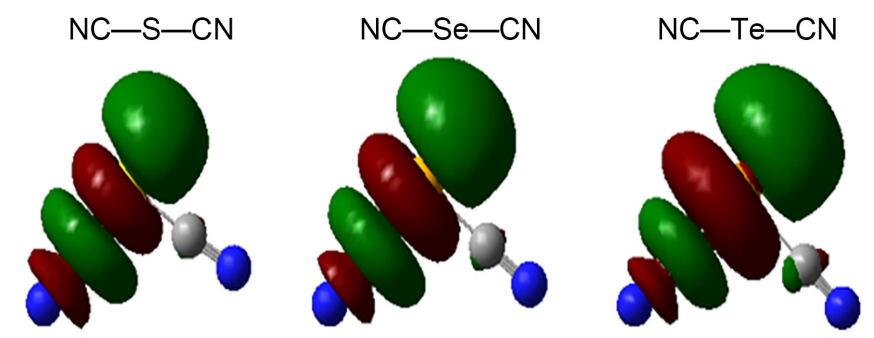

Figure 5. LUMO's examples for chalcogen-bond donors: CN-S-CN, $\mathrm{CN}-\mathrm{Se}-\mathrm{CN}$ and $\mathrm{CN}-\mathrm{Te}-\mathrm{CN}$.

Interestingly, the lowest unoccupied molecular orbital also lies along extension of the covalent bond X-R like MEP does. Thus, both MEP and LUMO of chalcogen-bond donor predict directional bonding of nucleophiles at divalent chalcogen atoms as previously reported (Pal et al. 2001 [1]; Lundemba et al. 2020 [27]).

\subsubsection{Interaction Energetics}

Values of interaction energy $\left(E_{\text {int }}\right)$ calculated using different theories are listed in Table 4.

Energy values are negative demonstrating attractive interactions between chalcogen donors and acceptors. Energies calculated with MP2 have values close to those calculated using B3LYP with dispersion correction. but markedly different to those without dispersion correction. That finding reveals that disper- 
sion forces play an important role in stabilizing chalcogen-bonded complexes. $E_{\text {int }}$ depends on chalcogen atoms and their environments similarly to bond length $(\Delta)$ and $V_{\text {s.max }}$. It increases according to $V_{\text {s.max }}$ in the sequence $\mathrm{S}<\mathrm{Se}$ for interactions involving $\sigma$-hole donors containing $\mathrm{S}$ and Se divalent atoms.

Table 4. Values of $E_{\text {int }}\left(\mathrm{kcal} \cdot \mathrm{mol}^{-1}\right), \theta\left(^{\circ}\right), \delta(\AA)$ and number of imaginary frequencies $\left(N_{f}\right)$.

\begin{tabular}{|c|c|c|c|c|c|c|c|c|c|}
\hline \multirow{2}{*}{ Methods } & & \multicolumn{2}{|c|}{ AMOREA } & \multicolumn{2}{|c|}{ KUYRIF } & \multicolumn{2}{|c|}{ VAMPEF } & \multicolumn{2}{|c|}{ FITLID } \\
\hline & & $S$ & $\mathrm{Se}$ & $S$ & $\mathrm{Se}$ & $S$ & $\mathrm{Se}$ & $S$ & $\mathrm{Se}$ \\
\hline \multirow{4}{*}{$\begin{array}{l}\text { B3LYP/6-311G } \\
\text { (3df, 2p) }\end{array}$} & $N_{v}$ & 1 & 0 & 1 & 0 & 0 & 1 & 0 & 0 \\
\hline & $E_{\text {int }}$ & -9.80 & -11.04 & -5.13 & -11.10 & -4.39 & -5.23 & -2.85 & -3.06 \\
\hline & $\delta$ & 3.21 & 3.23 & 3.37 & 3.16 & 3.35 & 3.43 & 4.21 & 4.17 \\
\hline & $\theta$ & 177 & 172 & 171 & 172 & 163 & 167 & 164 & 161 \\
\hline \multirow{4}{*}{$\begin{array}{c}\text { B3LYP-D3/6-311G } \\
\text { (3df, 2p) }\end{array}$} & $N_{f}$ & 1 & 1 & 0 & 0 & 0 & 0 & 0 & 0 \\
\hline & $E_{\text {int }}$ & -17.47 & -19.36 & -20.46 & -28.27 & -23.94 & -30.66 & -13.07 & -15.54 \\
\hline & $\delta$ & 3.13 & 3.15 & 3.23 & 3.05 & 3.17 & 2.95 & 3.87 & 4.06 \\
\hline & $\theta$ & 174 & 170 & 169 & 173 & 170 & 176 & 154 & 144 \\
\hline \multirow{4}{*}{$\begin{array}{c}\text { B3LYP-D3BJ/6-311G } \\
\text { (3df, 2p) }\end{array}$} & $N_{f}$ & 1 & 1 & 0 & 0 & 0 & 0 & 2 & 2 \\
\hline & $E_{\text {int }}$ & -18.15 & -20.37 & -21.34 & -32.49 & -27.36 & -39.85 & -14.09 & -16.86 \\
\hline & $\delta$ & 3.06 & 3.08 & 3.09 & 2.91 & 3.07 & 2.51 & 3.74 & 3.76 \\
\hline & $\theta$ & 171 & 171 & 172 & 173 & 169 & 177 & 154 & 152 \\
\hline \multirow{3}{*}{$\begin{array}{l}\mathrm{MP} 2 / 6-311 \mathrm{G} \\
\quad(3 \mathrm{df}, 2 \mathrm{p})\end{array}$} & $E_{\text {int }}$ & -19.93 & -21.24 & -25.10 & -34.66 & -36.22 & -62.50 & -15.59 & -- \\
\hline & $\delta$ & 3.01 & 3.05 & 2.98 & 2.82 & 2.89 & 2.26 & 3.47 & -- \\
\hline & $\theta$ & 172 & 168 & 171 & 173 & 171 & 171 & 159 & -- \\
\hline
\end{tabular}

Table 5 reports results of NBO analysis for some chalcogen-bonded complexes.

Table 5. Charge transfer and stabilizing energy $E^{(2)}$ of chalcogen interactions.

\begin{tabular}{|c|c|c|c|c|c|}
\hline $\mathrm{R}_{1}-\mathrm{S}-\mathrm{R}_{2}$ Complex & Chalcogen interaction & & & \multicolumn{2}{|c|}{$E^{(2)}\left(\mathrm{kJ} \cdot \mathrm{mol}^{-1}\right)$} \\
\hline & & \multicolumn{2}{|c|}{ B3LYP B3LYP-D3 } & BJ B3LYP-D3BJ & MP2 \\
\hline$(\mathrm{NC})_{2} \mathrm{~S}-\mathrm{NH}_{3}$ & $\mathrm{LP}(1) \mathrm{N} 2 \rightarrow \mathrm{BD}^{*}(1) \mathrm{S} 1-\mathrm{C} 7$ & 20.29 & 21.46 & 23.01 & 25.82 \\
\hline$(\mathrm{NC})_{2} \mathrm{~S}-\mathrm{O}\left(\mathrm{CH}_{3}\right)_{2}$ & $\mathrm{LP}(1) \mathrm{O} 6 \rightarrow \mathrm{BD}^{*}(1) \mathrm{S} 1-\mathrm{C} 2$ & 8.87 & 10.71 & 11.59 & 14.64 \\
\hline$(\mathrm{NC})_{2} \mathrm{~S}-\mathrm{NCH}$ & $\mathrm{LP}(1) \mathrm{N} 8 \rightarrow \mathrm{BD}^{*}(1) \mathrm{S} 1-\mathrm{C} 2$ & 8.16 & 7.78 & 9.50 & 11.72 \\
\hline \multirow[t]{2}{*}{$\mathrm{R}_{1}-\mathrm{Se}-\mathrm{R}_{2}$ Complex } & Chalcogen interaction & & & \multicolumn{2}{|c|}{$E^{(2)}\left(\mathrm{kJ} \cdot \mathrm{mol}^{-1}\right)$} \\
\hline & & \multicolumn{2}{|c|}{ B3LYP B3LYP-D3 } & BJ B3LYP-D3BJ & MP2 \\
\hline$(\mathrm{NC})_{2} \mathrm{Se}-\mathrm{NH}_{3}$ & $\mathrm{LP}(1) \mathrm{O} 6 \rightarrow \mathrm{BD}^{*}(1) \mathrm{S} 1-\mathrm{C} 2$ & 38.58 & 40.84 & 42.76 & 49.12 \\
\hline$(\mathrm{NC})_{2} \mathrm{Se}-\mathrm{O}\left(\mathrm{CH}_{3}\right)_{2}$ & $\mathrm{LP}(1) \mathrm{O} 6 \rightarrow \mathrm{BD}^{*}(1) \mathrm{S} 1-\mathrm{C} 2$ & 16.28 & 19.29 & 20.75 & 25.36 \\
\hline$(\mathrm{NC})_{2} \mathrm{Se}-\mathrm{NCH}$ & $\mathrm{LP}(1) \mathrm{N} 8 \rightarrow \mathrm{BD}^{*}(1) \mathrm{S} 1-\mathrm{C} 2$ & 15.06 & 14.23 & 17.36 & 20.75 \\
\hline
\end{tabular}


According to the results reported in Table 4. The chalcogen-bond consists of charge transfer (CT) from a nucleophile lone pair (LP) acting as $\sigma$-hole bond acceptor to an antibonding orbital $\left(\mathrm{BD}^{\star}\right) \mathrm{X}-\mathrm{R}$ of the chalcogen bond donor (Guo et al. 2015 [32]). Furthermore, orbital contributions $E^{(2)}$ associated with electron delocalisation between depend on chalcogen atoms increasing as expected in the sequence $\mathrm{S}<$ Se.

\section{Conclusions}

We investigated on the chalcogen bonding at divalent $\mathrm{S}$, Se and Te atoms in organic molecules, based on CSD analysis in conjunction with $a b$ initio calculations using some chemical models. The work aimed to enable a better understanding of the interaction nature, geometry and strength. Several conclusions can be drawn from the results obtained:

1) CSD surveys showed that nucleophile atoms N. O. F. P. Cl. As. Se. Te and I interacted with the divalent chalcogen atoms. A significant frequency of occurrence (FoO) was found for 7 subgroups with (C; C), (C. N) and (N. N) as the most common $\sigma$-hole bond donors and the $\mathrm{FoO}$ decreasing in the sequence (C; C) $>$ (N. N) $>$ (C. N).

2) FoO and geometry were dependent on the $R_{1}$ and $R_{2}$ substituents. Values of the $\Delta$ interaction distance ranged from $-0.052 \AA$ to $-0.512 \AA$ for sulphur, from $-0.086 \AA$ to $-1.017 \AA$ for selenium and from $-0.160 \AA$ to $-0.951 \AA$ for tellurium, while those of the angle $\theta$ were close to $170^{\circ}$ suggesting an attractive and nearly linear chalcogen interaction.

3) Ab initio calculations showed that the most positive electrostatic potential surfaces $\left(V_{S \text {.max }}\right)$ were located on chalcogens $(\mathrm{S} . \mathrm{Se} ; \mathrm{Te})$ in the extensions $\mathrm{X}-\mathrm{R}_{1}$ and $\mathrm{X}-\mathrm{R}_{2}$ bonds predicting directional and electrostatic interactions between the chalcogen atoms $\mathrm{X}$ and lone pairs of nucleophile atoms. LUMO orbitals of donors, with energy values decreasing in the sequence $\mathrm{Te}>\mathrm{Se}>\mathrm{S}$, were involved in interactions nucleophiles.

4) All values of the interaction energy $E_{\text {int }}$ were negative confirming the attractive nature of interaction. Comparison of $E_{\text {int }}$ values calculated with the different quantum mechanical methods suggested that dispersion interactions played an important role in stabilizing $\sigma$-hole-bonded complexes. NBO analysis revealed that the chalcogen interactions consisted of transfer of charge from a nucleophile lone pair to an X- $R_{1}$ and X- $R_{2}$ antibonding orbital.

The present study provides a reliable contribution to the structural chemistry of chalcogen-bonded complexes. The relatively marked strength of the chalcogen bond and its characteristic directionality should guide the use of divalent $\mathrm{S}$. Se and Te atoms in varied application areas like crystal engineering, drug design and supramolecular chemistry.

\section{Acknowledgements}

Albert L. Lundemba gratefully acknowledges support from the Cambridge Crystallographic Data Centre. 


\section{Conflicts of Interest}

The authors declare no conflicts of interest regarding the publication of this paper.

\section{References}

[1] Pal, D. and Chakrabarti, P. (2001) Non-Hydrogen Bond Interactions Involving the Methionine Sulfur Atom. Journal of Biomolecular Structure and Dynamics, 19, 115-128. https://doi.org/10.1080/07391102.2001.10506725

[2] Politzer, P., Murray, J.S. and Lane, P. (2007) $\sigma$-Hole Bonding and Hydrogen Bonding: Competitive Interactions. International Journal of Quantum Chemistry, 107, 3046-3052. https://doi.org/10.1002/qua.21419

[3] Bleiholdder, C., Werz, D.B., Köppel, H. and Gleiter, R. (2006) Theoretical Investigations on Chalcogen-Chalcogen Interactions: What Makes These Nonbonded Interactions Bonding? Journal of the American Chemical Society, 128, 2666-2674. https://doi.org/10.1021/ja056827g

[4] Clark, T., Hennemann, M., Murray, J.S. and Politzer, P. (2007) Halogen Bonding: the $\sigma$-Hole. Journal of Molecular Modeling, 13, 291-296.

https://doi.org/10.1007/s00894-006-0130-2

[5] Ramos, L.A., Ulic, S.E., Romano, R.M., Erben, M.F., Lehmann, C.W., Bernhardt, E., Beckers, H., Willner, H. and Della Vedova, C.O. (2010) Vibrational Spectra, Crystal Structures, Constitutional and Rotational Isomerism of $\mathrm{FC}(\mathrm{O}) \mathrm{SCN}$ and $\mathrm{FC}(\mathrm{O}) \mathrm{NCS}$. Inorganic Chemistry, 49, 11142-11157. https://doi.org/10.1021/ic101741e

[6] Politzer, P., Murray, J.S. and Bulat, F.A. (2010) Average Local Ionization Energy: A Review. Journal of Molecular Modeling, 16, 1731-1742. https://doi.org/10.1007/s00894-010-0709-5

[7] Politzer, P., Murray, J.S. and Clark, T. (2013) Halogen Bonding and Other $\sigma$-Hole Interactions: A Perspective. Physical Chemistry Chemical Physics, 15, 11178-11189. https://doi.org/10.1039/c3cp00054k

[8] Politzer, P. and Murray, J.S. (2013) Halogen Bonding: An Interim Discussion. ChemPhysChem, 14, 278-294. https://doi.org/10.1002/cphc.201200799

[9] Politzer, P., Murray, J.S., Janjie, G.V. and Zarie, S.D. (2014) $\sigma$-Hole Interactions of Covalently-Bonded Nitrogen, Phosphorus and Arsenic: A Survey of Crystal Structures. Crystals, 4, 12-31. https://doi.org/10.3390/cryst4010012

[10] Pandiyan, B.V., Deepa, P. and Kolandaivel, P. (2016) Studies on the $\sigma$-Hole Bonds (Halogen, Chalcogen, Pnicogen and carbon Bonds) Based on the orientation of Crystal Structure. Molecular Physics, 2016, Article ID: 1255796.

[11] Zabardasti, A., Afrouzi, H., Kakanejadifard, A. and Jamshidi, Z. (2017) The S...P Noncovalent Interaction: Diverse Chalcogen Bonds. Molecular Physics, 38, 249-263. . https://doi.org/10.1080/17415993.2016.1275634

[12] Bauza, A. and Frontera, A. (2018) Chalcogen Like-Like Interactions Involving Trisulphide and Triselenide Compounds: A Combined CSD and Ab Initio Study. Molecules, 23, 699. https://doi.org/10.3390/molecules23030699

[13] Bauza, A. and Frontera, A. (2019) Halogen and Chalcogen Bond Energies Evaluated Using Electro Density Properties. ChemPhysChem, 20, 1-7.

[14] Bauza, A. and Frontera, A. (2020) $\sigma / \pi$-Hole Noble Gas Bonding Interactions: Insights from Theory and Experiment. Coordination Chemistry Reviews, 404, Article ID: 213112. https://doi.org/10.1016/j.ccr.2019.213112 
[15] Murray, J.S., Lane, P., Clark, T. and Politzer, P. (2007) $\sigma$-Hole Bonding: Molecules Containing Group VI Atoms. Journal of Molecular Modeling, 13, 1033-1038. https://doi.org/10.1007/s00894-007-0225-4

[16] Murray, J.S. and Politzer, P. (2011) The Electrostatic Potential: An Overview. Wiley Interdisciplinary Reviews. Computational Molecular Science, 1, 153-163.

https://doi.org/10.1002/wcms.19

[17] Politzer, P. and Murray, J.S. (2017) $\sigma$-Hole Interactions: Perspectives and Misconceptions. Crystals, 7, 212-227. https://doi.org/10.3390/cryst7070212

[18] Goettel, J.T. and Gerken, M. (2016) Synthesis and Characterization of Adducts be-

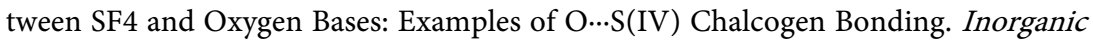
Chemistry, 55, 12441-12450. https://doi.org/10.1021/acs.inorgchem.6b02373

[19] Karjalainen, M.M., Perez, C.S., Rautiainen, J.M., Oilunkaniemi, R. and Laitinen, R.S. (2016) Chalcogen-Chalcogen Secondary Bonding Interactions in Trichalcogenide Ferrocenophanes. CrystEngComm, 18, 4538-4545.

https://doi.org/10.1039/C6CE00451B

[20] Bruno, I.J., Cole, J.C., Edgington, P.R., Kessler, M., Macrae, C.F., McCabe, P., Pearson, J. and Taylor, R. (2002) New Software for Searching the Cambridge Structural Database and Visualizing Crystal Structures. Acta Crystallographica Section B, 58, 389-397. https://doi.org/10.1107/S0108768102003324

[21] Macrae, C.F., Bruno, I.J., Chisholm, J.A., Edgington, P.R., McCabe, P., Pidcock, E., Rodriguez-Monge, L., Taylor, R., van de Streek, J. and Wood, P.A. (2008) Mercury CSD 2.0-New Features for the Visualization and Investigation of Crystal Structures. Journal of Applied Crystallography, 41, 466-470. https://doi.org/10.1107/S0021889807067908

[22] Macrae, C.F., Edgington, P.R., McCabe, P., Pidcock, E., Shields, G.P., Taylor, R., Towler, M. and van de Streek, J. (2006) Mercury: Visualization and Analysis of Crystal Structures. Journal of Applied Crystallography, 39, 453-457. https://doi.org/10.1107/S002188980600731X

[23] Sykes, R.A., McCabe, P., Allen, F.H., Battle, G.M., Bruno, I.J. and Wood, P.A. (2011) New Software for Statistical Analysis of Cambridge Structural Database Data. Journal of Applied Crystallography, 44, 882-886. https://doi.org/10.1107/S0021889811014622

[24] Wood, P.A., Pidcock, E. and Allen, F.H. (2008) Interaction Geometries and Energies of Hydrogen Bonds to $\mathrm{C}=\mathrm{O}$ and $\mathrm{C}=\mathrm{S}$ Acceptors: A Comparative Study. Acta Crystallographica Section B, 64, 491-496. https://doi.org/10.1107/S0108768108015437

[25] Bondi, A. (1964) Van der Waals Volumes and Radii. The Journal of Physical Chemistry, 68, 441-451. https://doi.org/10.1021/j100785a001

[26] Murray, J.S. and Politzer, P. (2011) The Electrostatic Potential: An Overview. Wiley Interdisciplinary Reviews: Computational Molecular Science, 1, 153-163.

https://doi.org/10.1002/wcms.19

[27] Lundemba, A.S., Bibelayi, D.D., Wood, P.A., Pradon, J. and Yav, Z.G. (2020) $\sigma$-Hole Interactions in Small-Molecule Compounds Containing Divalent Sulfur Groups R1-S-R2. Acta Crystallographica Section B, 76, 707-718. https://doi.org/10.1107/S2052520620008598

[28] Grimme, S.J. (2006) Semiempirical GGA-Type Density Functional Constructed with a Long-Range Dispersion Correction. Journal of Computational Chemistry, 27, 1787-1799. https://doi.org/10.1002/jcc.20495

[29] Politzer, P. and Murray, J.S. (2009) An Overview of $\sigma$-Hole Bonding, an Important 
and Widely-Occurring Noncovalent Interaction. In: Leszczynski, J. and Shukla, M.K., Eds., Practical Aspects of Computational Chemistry, Springer, Heidelberg, 149-163. https://doi.org/10.1007/978-90-481-2687-3 6

[30] Murray, J.S., Lane, P. and Politzer, P. (2009) Expansion of the $\sigma$-Hole Concept. Journal of Molecular Modeling, 15, 723-729.

https://doi.org/10.1007/s00894-008-0386-9

[31] Murray, J.S., Macaveiu, L. and Politzer, P. (2014) Factors Affecting the Strengths of $\sigma$-Hole Electrostatic Potentials. Journal of Computational Science, 5, 590-596. https://doi.org/10.1016/j.jocs.2014.01.002

[32] Guo, X., Liu, Y.W., Li, Q.Z., Li, W.Z. and Cheng, J.B. (2015) Competition and Cooperativity between Tetrel Bond and Chalcogen Bond in Complexes Involving F2CX (X = Se and Te). Chemical Physics Letters, 620, 7-12.

https://doi.org/10.1016/j.cplett.2014.12.015 